\title{
Para repensar las Juntas Militares de $1917^{*}$
}

\author{
Alberto Bru Sánchez-Fortún \\ Investigador particular
}

RESUMEN: Este trabajo pretende reinterpretar las Juntas Militares de 1917, insertándolas en la reflexión que el doctor Villacorta Baños dedicó hace veinticinco años al corporativismo defensivo que distintos grupos de profesionales y burócratas desarrollaron frente al Estado y la sociedad durante la última década del siglo XIX y las dos primeras del XX. Con este enfoque, ignorado hasta la fecha en los estudios sobre la institución castrense, negaremos que las Juntas constituyeran otra más de las muchas intervenciones del Ejército para cambiar la política del momento. Representarían, en cambio, un movimiento corporativo de defensa de la carrera profesional de sus asociados, puesta siempre en cuestión por el entramado caciquil que resultaba ser la naturaleza íntima del Estado de la Restauración, problema que el Ejército compartía con el resto de los empleados públicos. Sin embargo, la extrema pluralidad de la corporación castrense la incapacitó para levantar una única organización reivindicativa. La escala, ni siquiera el cuerpo, fue quien articuló el dividido fenómeno juntero, propiciando la existencia de diferentes «Juntas» con intereses corporativos a menudo contrapuestos. De modo que, en lugar de amenazar al Estado con la poderosa unidad del Ejército, evidenciaron su desunión, por más que procuraran administrar desacuerdos y desactivar pugnas.

PALABRAS CLAVE: Restauración; caciquismo; corporativismo; ejército español; cuerpos y escalas; juntas militares.

\section{Rethinking the 1917 Military Juntas}

ABSTRACT: The aim of this paper is to reinterpret the 1917 Military Juntas, analyzing them within the framework of Dr. Villacorta Baños' defense, twenty-five

* Abreviaturas de archivo: Archivo General Militar de Ávila (AGMAV). Archivo General Militar de Segovia (AGMS). 
years ago, of the defensive corporatism that various professional and bureaucratic groups developed in opposition to the state and society during the last decade of the 19th century and the first two decades of the 20th century. From this viewpoint, which up to the present has been ignored in studies of the military institution, we shall deny that the Juntas were just another of the many interventions of the Army to change the politics of the moment. On the contrary, we claim they represent a corporate movement aimed at defending the professional career of their associates, a career always questioned by the framework of cacique power abuse, which was the inner nature of the state during the Spanish Restoration; a problem the Army shared with the rest of public employees. Nonetheless, due to its extreme variety, the military corporation was unable to put together one single bargaining association. It was ultimately the scale, not the corps, which gave an aim to the divided junta movement. Thus, it propitiated the existence of various "Juntas" with corporate interests which were often conflicting. And so, instead of threatening the State with the powerful unity of the Army, they made their division evident, however much they tried to solve disagreements and settle conflicts.

KEY WORDS: Restoration; caciquismo; corporatism; Spanish army; Corps and Scales; Military Juntas.

\section{INTRODUCCIÓN}

Las Juntas de Defensa, emergidas a la vida política española en la Crisis de 1917, constituyen un tema que no ha sido soslayado por los historiadores interesados en la historia institucional del Ejército español y en sus relaciones con el entramado político de la Restauración. Los primeros trabajos abordaron el fenómeno juntero como otro caso - el enésimo - de intervencionismo militar en la política española, centrándose en su papel de actor desencadenante de aquella crisis, y en sus relaciones con la Asamblea de Parlamentarios y con la Huelga General de Agosto ${ }^{1}$. Más tarde, en los años 80, el estudio de las Juntas comenzó a cobrar profundidad: se exploraron sus causas, antecedentes y desarrollo dentro de la lógica interna de la corporación castrense, sin descuidar su contribución a la descomposición política de la Monarquía ${ }^{2}$; pero, a nuestro juicio, una mejor comprensión exige repensarlas como un fenómeno surgido del profundo malestar de unos cuerpos de burócratas cuyos integrantes, no por llevar uniforme, dejaban de ser meros funcionarios al ser-

1 PABÓN, 1952; luego LACOMBA AVELLÁN, 1970.

2 Los trabajos de ese periodo que nos parecen más útiles son los de BOYD, 1990, quizás el intento más serio de explicar las relaciones entre el entramado castrense, la clase política y la sociedad española; y PUELL DE LA VILLA, 1986, en donde mejor se explican los antecedentes lejanos e inmediatos del fenómeno juntero, pero su investigación no va más allá de 1917. 
vicio del Estado. Sus problemas y sus organizaciones de defensa - las mismas Juntas, por ejemplo - no fueron diferentes de los de otros colectivos de burócratas civiles, sino que marcharon muy a menudo en paralelo, inspirándose unos a otros, conformando un movimiento corporativo funcionarial difuso, discontinuo, disperso, con un grado de consolidación diferente, mayor si hablamos de cuerpos facultativos o técnicos, menor si se trata de cuerpos auxiliares o generales, pero siempre comprometido en la lucha por la estabilidad en el empleo y por la defensa de una verdadera carrera profesional libre de injerencias caciquiles, lo que a menudo propició intentos de patrimonializar determinados servicios públicos o funciones administrativas. Fue, en definitiva, un esfuerzo paralelo al de la construcción del propio Estado contemporáneo, y que ocupó a varias generaciones de burócratas, desplegándose a lo largo de toda la segunda mitad del siglo XIX y las primeras décadas del XX. Esta perspectiva general quedó fijada ya a finales de aquella década de los ochenta, gracias a un libro del profesor Villacorta Baños, que no pretendía aludir especialmente a la corporación castrense ${ }^{3}$. Tal vez por ello, el único trabajo posterior centrado en las Juntas de Defensa - una tesis doctoral, que resulta, además, la única obra referida a ellas exclusivamente - la ha ignora$\mathrm{do}^{4}$. Nuestra intención, por tanto, es mejorar la comprensión de algunas de las cuestiones relativas a las Juntas Militares desde ese enfoque que las inserta en los vaivenes de un movimiento de defensa corporativa más amplio. Para ello debemos comenzar caracterizando al militar como un empleado público más.

\section{EL MILITAR COMO EMPLEADO PÚBLICO}

Con el advenimiento de los Borbones al trono español, la administración ordinaria del reino quedó en manos de la función militar, integrada por el único colectivo con formación adecuada, número suficiente, y estricta sujeción al monarca en todo lo referido a nombramientos, ascensos y destinos. De este modo, la oficialidad del Ejército se constituyó durante el siglo XVIII en «el principal vivero de funcionarios del Estado ${ }^{5}$, y el mejor instrumento que tenía la Corona a su disposición para neutralizar los privilegios jurisdiccionales de la aristocracia y el clero.

En el siglo siguiente la carrera militar se hizo poco a poco más reglada, menos dependiente de la arbitrariedad del rey o de los altos mandos del Ejército. La mayoría de los oficiales, incluso en la primera mitad del siglo XIX, tenían como única fuente de ingresos el salario que le proporcionaba la profe-

3 VILLACORTA BAÑOS, 1989.

4 ALONSO IBÁÑEZ, 2004.

5 PUELL DE LA VILLA, 2000: 22. 
sión. Una profesión que se iría masificando cada vez más en detrimento del salario y de la carrera. Mantenerse dentro de la categoría de las clases medias resultó difícil para los oficiales de baja graduación. Aun así, el perfil del colectivo castrense, ya durante el reinado de Isabel II, se transformó en el de un cuerpo profesional al servicio del Estado, y sus integrantes dejaron de ser meros servidores del monarca. Al mismo tiempo, los oficiales consiguieron durante estos años que el Estado corporativizara la carrera de las armas, de forma que acabaron por suplantar a la totalidad de la institución castrense ${ }^{6}$.

Esta creciente profesionalización exigía consolidar una seguridad en el empleo desconocida en otros ramos de la Administración. En 1821, la primera, y efímera, Ley Constitutiva del Ejército declaraba en su artículo 71: «Ningún militar podrá ser privado ni suspenso de su graduación, ni del sueldo que por ella disfrute, sino por causa legalmente probada y sentenciada». En 1835 el artículo $1^{\circ}$ del «Real decreto fijando el sistema de ascenso en el ejército» repetía la misma idea ${ }^{7}$. Y en algún momento posterior se quiso que la adjudicación de muchos de los destinos quedara libre de todo espíritu de partido, como, por ejemplo, tras el final traumático de la regencia de Espartero ${ }^{8}$. Finalmente, la Ley Constitutiva del Ejército de 1878 declaraba en su artículo $1^{\circ}$ que el Ejército constituía «una de las carreras del organismo del Estado»; y en su artículo 30 que: «El empleo militar es una propiedad con todos los derechos y goces que las leyes y reglamentos consignan». Era, pues, indudable: el profesional de las armas se había convertido en un servidor del Estado, en un funcionario.

Además, la aparición de academias o colegios, en los que las clases medias y bajas de la sociedad ingresaban por oposición para recibir una enseñanza reglada y progresivamente tecnificada en régimen de internado y el encasillamiento, al terminar los estudios, en un escalafón protector que regularía ascensos, destinos y retiros generaron una conciencia profesional de identidad más excluyente que la derivada de los vínculos estamentales que cohesionaron el cuerpo de oficiales durante la etapa anterior ${ }^{9}$.

Paralelamente, la consolidación del Estado liberal exigió también el desarrollo de un funcionariado civil con problemas semejantes a los de sus compañeros militares. La Administración central se fue estructurando durante

6 PUELL DE LA VILLA, 2006: 446.

7 GACETA DE MADRID (a partir de ahora G.M.) no 218 de 5 de agosto de 1835, pp. 870-871.

8 G.M. $\mathrm{n}^{\mathrm{o}} 3265$ de 30 de agosto de 1843 p. 1: «Disponiendo que al formar los cuadros de los cuerpos del arma citada, elija para dar entrada en ellos á los jefes y oficiales que mayor capacidad y aptitud reúnan, así como mayores méritos y servicios, cualquiera que haya sido el partido al que hayan podido pertenecer»».

9 PUELL DE LA VILLA, 2000: 73. 
toda la segunda mitad del siglo XIX y los primeros años del siglo siguiente alrededor de una matriz vertebradora del personal que recibió el nombre de «cuerpo», quizás un préstamo de la organización militar ${ }^{10}$. Estos «cuerpos»se organizarán en torno a una relación de puestos de trabajo denominada «plantilla», y a la clasificación de su personal activo en función de su categoría y antigüedad —el escalafón-, lo que producirá sueldos y derechos pasivos diferentes. La implantación progresiva de este esquema se realizará lentamente entre 1852, fecha de lo que podríamos considerar el primer estatuto de funcionarios, debido a Bravo Murillo y la ley de presupuestos de 1892 y otras disposiciones ministeriales inmediatamente posteriores ${ }^{11}$. La historia de estos nuevos cuerpos civiles - los denominados «cuerpos generales administrativos», sobre todo- marchó en paralelo con la de las armas generales (Infantería y Caballería). Fue una historia de lucha por la permanencia en el empleo para poder hacer efectivo el derecho a la carrera. Sin embargo, el relativo éxito en este punto por parte de la corporación castrense llegó a tener en ocasiones indeseables contrapartidas. Por ejemplo, la integración de los oficiales carlistas derrotados en los escalafones del ejército victorioso los hipertrofió irreversiblemente, imposibilitando una adecuada carrera profesional, al menos en las armas generales. De modo que si los cuerpos civiles padecieron la lacra de las cesantías, el exceso de oficiales propició el subempleo y la aparición de un sorprendente correlato militar de la figura civil del cesante. Nos referimos al oficial de reemplazo a media paga, sobreabundante durante los dos últimos tercios del siglo XIX ${ }^{12}$.

También el fantasma de las amortizaciones persiguió a ambos grupos en determinados momentos de su historia, malogrando sus posibilidades de carrera. Por ejemplo, tras nuestro colapso militar en Cuba y Filipinas, la necesidad de pagar los gastos militares que nos exigió la contienda -2300 millones de pesetas de entonces, que hicieron subir la deuda nacional a cimas impensadas $^{13}$ _, espoleó a los ministros de la guerra a aplicar sucesivas oleadas de amortizaciones de vacantes, que solían oscilar entre el $25 \mathrm{y}$ el $75 \%^{14}$; y en un momento en que varios miles de oficiales que habían prestado servicio en ultramar volvían a la península casi mendigando una vacante. Hubo que recolocar alrededor de 3500 oficiales de la escala activa en destinos burocráticos,

10 CARRASCO CANALS, 1975: 121-123 y 128-131.

11 MORAL RUIZ; PRO RUIZ y SUÁREZ BILBAO, 2007: 117. VILLACORTA BANOS, 1989: 70-71.

12 Las cesantías en la administración pública están matizadas en CARRASCO CANALS, 1975: 117. Sobre la cantidad de oficiales en situación de reemplazo en distintos momentos del siglo XIX y su incidencia en el presupuesto de Guerra se puede ver: FERNÁNDEZ BASTARRECHE, 1978: 76-77, 80-81 y 83.

13 PAYNE, 1968: 418.

14 CACHINERO, 10, (Madrid 1988): 163-166. 
al tiempo que se propiciaba el retiro de 5000 de los 8000 oficiales de la escala de reserva retribuida ${ }^{15}$. Pero la catástrofe colonial no produjo sólo un excedente de funcionarios militares, también hubo que repatriar un contingente no despreciable de funcionarios civiles. Y si se disolvieron unidades militares, también se disolvió todo un ministerio: el de Ultramar ${ }^{16}$. El resultado final de esta anómala inyección de personal activo y pasivo en ambos grupos de funcionarios, en un momento de economías forzadas por la necesidad de pagar la exorbitante deuda de la guerra perdida, se concretó durante los primeros años del siglo XX en un panorama dominado por la destrucción de vacantes —las amortizaciones - ; la generalización de las cesantías; las situaciones de reemplazo o subempleo militar, incluso los retiros mejor o peor incentivados.

Sin embargo, la más severa amenaza contra el empleo y la carrera de los burócratas españoles no provenía del azar catastrófico de guerras perdidas o ganadas. La base fundamental del edificio de la Restauración —el caciquismo y sus redes clientelares - era también la causa de que la carrera profesional del funcionario, de los cuerpos generales sobre todo, dependiera en mayor medida de su «vinculación a camarillas burocráticas, patronazgos e influencias políticas» que no «a normas objetivas de decurso profesional» ${ }^{17}$. Algo muy parecido ocurría en la corporación castrense, amenazada, además, por una necesaria reconversión de la defensa nacional que dotase de eficacia al Ejército, la cual supondría feroces recortes de plantilla y empantanamiento de carreras. La propia inoperancia del sistema político desactivó lo más agresivo de las reformas de los ministros Echagüe y Luque. Aún así, la situación interna de los cuerpos de oficiales seguía siendo compleja y desequilibrada: padecían una fuerte endogenia, y presentaban ya consolidadas ciertas dinastías de militares de prestigio; aunque al mismo tiempo estaban absorbiendo, sobre todo en las armas generales, a miles de hijos de brigadas y sargentos, generando unos escalafones imposibles de ajustar a las plantillas. En tales condiciones, los destinos y sus salarios correspondientes, la misma carrera militar, dependían también de toda una serie de caciques de uniforme, más o menos influyentes según su jerarquía. Por eso las Juntas de Defensa surgidas en 1917, intentando proteger la carrera profesional de interferencias externas, nacieron excluyendo al generalato, incluso miraron con hostilidad a determinados generales «políticos». Por encima de ese puñado de generales, la misma Corona, encarnada ya en Alfonso XIII, resultó ser el más poderoso de los caciques, en su intento de patrimonializar el cuerpo de oficiales para obtener una plataforma política independiente de los renqueantes partidos dinásticos ${ }^{18}$.

\footnotetext{
15 SOLDEVILLA, 1901: 103-104. CARDONA, 1990: 123.

16 VILLACORTA BAÑOS, 1989: 151.

17 VILLACORTA BAÑOS, 1989: 69.

18 BRU SÁNCHEZ-FORTÚN, 6 (2006): 71-96.
} 
De ahí la necesidad de integrarse en un escalafón ordenado por antigüedad sentida por los empleados públicos, fueran civiles o militares; porque así puede producirse «el reconocimiento oficial del lugar privativo del funcionario en el Estado», dotándole de inamovilidad en su puesto, y defendiéndole del «sistema de botín político imperante durante mucho tiempo en la cobertura de los empleos públicos» ${ }^{19}$. Además, el escalafón resulta esencial para regular los ascensos y permite, por tanto, la existencia de una carrera funcionarial reglada. Pero conseguir el escalafonamiento oficial y público de los funcionarios administrativos exigió una lucha constante a lo largo de toda la segunda mitad del siglo XIX y primeros años del siglo siguiente contra los intereses y las intromisiones de la pequeña política caciquil. En cambio, esa necesidad se atendió mucho antes en el mundo castrense, justamente por estar ligada al tema capital de los ascensos. Así, la Infantería y la Caballería, urgidas por la Primera Guerra Carlista, comenzaron a desarrollar sus respectivos escalafones generales, gracias a dos reales decretos, el primero, el de ascensos de 1835 ya mencionado, y el segundo, del año siguiente ${ }^{20}$, en los que por primera vez se fijaba que los ascensos, por antigüedad o por elección, se realizaran teniendo en cuenta el escalafón general de cada arma, y no sobre el particular de cada unidad, como había estado sucediendo hasta entonces, al menos hasta el empleo de capitán inclusive ${ }^{21}$.

En consecuencia, terminada la Primera Guerra Carlista, los escalafones habían dejado de ser particulares de cada unidad y se habían transformado en generales de toda el arma; su confección se había sustraído a las unidades y pasaba a ser privativa del órgano director de ese arma o cuerpo ${ }^{22}$; los oficia-

\section{VILLACORTA BAÑOS, 1989: 70.}

20 Ver el R.D. mencionado en la nota 7, y el Real decreto de 26 de abril de 1836 «relativo á la provisión de vacantes en el ejército», publicado en la G.M. no 500 de 4 de mayo de 1836 , p. 1. El primero de ambos decretaba en el artículo 21 que «de subteniente á coronel inclusive se ascenderá en todos los cuerpos por el escalafón general de cada arma». El segundo, reconociendo la imposibilidad de mantener en tiempo de guerra el pleno vigor del anterior decreto, matizaba en su artículo 10 que la «operación... de los ascensos, se verificará por el escalafón general de armas ó por cuerpos, según sus reglamentos particulares».

21 Todavía el artículo 46 de la efímera Ley Constitutiva del Ejército de 9 de junio de 1821 obligaba a que los ascensos de sargento segundo a capitán inclusive se dieran en el mismo regimiento. Por cierto, su artículo 67 consagraba la «escala de rigurosa antigüedad» para los cuerpos facultativos (Artillería, Ingenieros y, luego, Estado Mayor), cosa que se volvería a repetir en el artículo 26 del ya citado Real decreto sobre ascensos de 1835.

22 Así, una circular de la Inspección General de Infantería de 2 de noviembre de 1843 revalidaba otra anterior de 27 de noviembre de 1841, «en que se mandó que dejara de remitirse la lista de antigüedad de señores jefes, oficiales, sarjentos (sic) primeros y cadetes» puesto que «no siendo los ascensos por cuerpos sino por escalafón jeneral (sic) en el arma, y pudiendo este llevarse con exactitud en esta inspección según el resultado del alta y baja, es inútil molestar a los cuerpos con la formación de más listas que no son necesarias». Ver EL BOLETÍN DEL EJÉRCITO (Madrid) de 2 de noviembre de 1843, p. 2. 
les, finalmente, adquirían la exacta conciencia de pertenecer a una corporación más amplia que el mero regimiento; una corporación autorregulada por órganos propios, como la inspección general (a partir de 1847 dirección general), y con una puerta de entrada claramente establecida: el colegio o academia del cuerpo, en cuya salida se iniciaba la virtualidad del escalafón. Pero, aunque la lealtad corporativa de los oficiales había dejado de focalizarse en la unidad y parecía residir en el cuerpo, quedaba aún un largo camino - que, desde luego, antes de 1936 no pudo terminar de recorrerse - para que el objeto de esa lealtad fuera el conjunto del Ejército. De todos modos, hubo que esperar hasta la década de 1890 para que se publicaran anualmente en un único tomo los escalafones de todas las armas y cuerpos del Ejército. Durante los cincuenta años anteriores aparecieron los de cada uno de ellos por separado, y no siempre con periodicidad anual, ni de una manera oficial. Así, en diciembre de 1842 se publicó el primer escalafón de los jefes y oficiales del Arma de Infantería. La Caballería hubo de esperar a 1845. De todos modos, parece que los mucho más reducidos cuerpos facultativos (Artillería e Ingenieros) ya agrupaban a sus componentes por antigüedad en escalafones confeccionados en el siglo anterior ${ }^{23}$.

\section{CORPORATIVISMO Y JUNTAS}

Los funcionarios civiles y militares debieron enfrentarse desde el principio a la intervención de «la política» y de las relaciones clientelares en la vida interna de sus cuerpos y escalas. No es cierto el cliché ampliamente difundido que quiere hacernos creer que el movimiento reivindicativo de los funcionarios civiles fue la cola del cometa juntero de 1917, aunque sí lo es que el viejo asociacionismo funcionarial adoptó el modelo organizativo de las Juntas militares poco después de su salida a la luz pública y, evidentemente, experimentó entonces un súbito incremento de afiliaciones. Pero es la realidad que, desde fines del siglo XIX, los cuerpos generales de la Administración civil ya comenzaron a desarrollar un difuso y discontinuo movimiento corporativo. Soñaban en constituir «cuerpos técnicos», con escalafones regidos por la antigüedad; sólidos lazos de asociación entre sus miembros; y plena sumisión a la disciplina de tribunales de honor propios, que excluyeran intromisiones ajenas $^{24}$, ideal que no se alejaba mucho del que quisieron imponer las Juntas

23 CAPEL; SÁNCHEZ; y MONCADA, 1988: 44, nos informa que el primer escalafón del cuerpo de Ingenieros podría haberse realizado en 1726. En cuanto al Cuerpo de Artillería, la biblioteca de su Academia en Segovia alberga un manuscrito con el escalafón de 1783, aunque en VIGÓN, 1947, vol. II: 26, hallamos que los tres primeros escalafones del Cuerpo de Artillería se imprimieron en 1805, 1806 y 1808.

24 VILLACORTA BAÑOS, 1989: 154. 
de Defensa en 1917 para las armas generales, las cuales nunca tuvieron empacho en exigir para sí los avances en la vida corporativa obtenidos por otros cuerpos civiles. En 1912, por ejemplo, en pleno debate político sobre los ascensos de guerra, La Correspondencia Militar, periódico portavoz de los intereses de la Infantería y la Caballería, se congratulaba de que el gobierno hubiera concedido algo parecido a la escala cerrada a la carrera judicial y fiscal y reclamaba el mismo trato para sus patrocinados ${ }^{25}$. También aquel mismo año, el periodista y diputado Leopoldo Romeo anunciaba en La Correspondencia de España que presentaría próximamente una proposición de ley que asegurase la escala cerrada para todos los cuerpos civiles o militares no regulados por oposición, y ponía de relieve cómo ambos colectivos compartían los mismos problemas y anhelos ${ }^{26}$.

Pero el asociacionismo de los funcionarios civiles a veces degeneró, sobre todo a partir de la Ley de Autorizaciones de febrero de 1917, en grupos de presión corporativos que disputaban al propio gobierno el reparto y la gestión del maná presupuestario. Aquejadas como estaban de una concepción patrimonializada del servicio público - y la misma grave enfermedad padecían las Juntas Militares de Defensa-, estos grupos se especializarán en reorganizaciones de plantillas siempre más atentas a las necesidades económicas del personal que a las del servicio, generando graves descompensaciones en la organización administrativa y completo descontrol del gasto público ${ }^{27}$. Éstas exactamente fueron las consecuencias a medio plazo de la Ley de Bases para la reorganización de Ejército de 1918, porque las Juntas Militares fueron también un grupo de presión corporativo siempre interesado en asegurarse suculentas porciones del presupuesto estatal. Además, tanto esa ley como la Ley de Bases sobre Funcionarios de la Administración Civil del Estado, inmediatamente posterior, suponían en la estrategia del gobierno Maura una apuesta por la reconducción económica de los conflictos con los empleados públicos: a cambio de salario, estabilidad en el empleo y regulación de las cesantías, los funcionarios debían olvidarse del libre ejercicio de sus capacidades asociativas.

Pero el distinto peso del juntismo civil y del militar se puede notar en que éste último no debió pagar ninguna contrapartida por las reformas que arrancó. Como veremos, aunque La Cierva solicitó su disolución, las Juntas Militares se la negaron. En definitiva, y es la opinión del doctor Villacorta, lo que el poder ofreció en aquellos años al juntismo civil o militar fue en ambos casos una transacción, apresuradamente aceptada por unos y otros, en la que las

25 LA CORRESPONDENCIA MILITAR de 21 y 24 de junio de 1912, ambas en p.1.

${ }^{26} L A$ CORRESPONDENCIA DE ESPAÑA de 16 de mayo de 1912, p.1. Su proposición de ley, que no prosperó en el DIARIO DE SESIONES DE CORTES. CONGRESO DE LOS DIPUTADOS n $\mathrm{n}^{\circ} 119$, Apéndice $7^{\circ}$, de 22 de mayo de 1912.

27 VILLACORTA BAÑOS, 1989: 336. 
concesiones económicas serían suficientes para subordinarlos al sistema de control político y de distribución de poder burocrático de la Restauración ${ }^{28}$. Sin embargo, en nuestra opinión, las divisiones internas de la galaxia castrense en general, y de la Infantería en particular - junteros contra africanistas-, exacerbadas por la situación en Cataluña, y una guerra colonial que terminaría desembocando en la catástrofe de Melilla, volvieron insuficiente la transacción ofrecida al juntismo militar.

Ambos juntismos, el civil y el castrense, sufrieron un proceso de organización semejante, salvo el secretismo con el que se fraguó el segundo, $\mathrm{y}$, sobre todo, resultaron ser fundamentalmente idénticos, tanto desde el punto de vista político, como desde el punto de vista social. Dicho esto, sin embargo, salta a la vista que el decisivo peso histórico del Ejército en el triunfo de la revolución liberal y en el desarrollo del Estado contemporáneo, la voluntad del reysoldado de crearse, a costa de la corporación militar, una plataforma política propia, distinta de los partidos dinásticos, y el monopolio castrense de la gestión del orden público, concedieron a las Juntas Militares de Defensa un protagonismo político del que casi nunca pudo disfrutar el corporativismo civil29.

Otra diferencia, y no la menor, entre los dos movimientos juntistas tuvo que ver con la diferente estrategia de confrontación con el poder que desarrollaron. El juntismo civil fue mucho más dado al enfrentamiento abierto, incluyendo el recurso a la huelga. En cambio, el juntismo militar, que coincidía con las organizaciones de funcionarios civiles en levantar la bandera de la «moralidad y justicia» —el lema anticaciquil por antonomasia-, no lograba acercarse sin aprensión a métodos más propios de sindicalistas que de caballeros. Por lo tanto, para defender sus intereses corporativos se decantó por la presión subterránea sobre el Estado; seguramente porque el Estado puede sobrevivir a un enfrentamiento abierto con los telegrafistas, por ejemplo; pero no a otro librado contra sus propias instituciones militares; y las corporaciones no quieren acabar con el Estado, sino utilizarlo en su favor o, al menos, evitar sus injerencias indeseables ${ }^{30}$. Si las Juntas emergieron el 1 de junio de 1917 no fue porque lo desearan — no pretendían formalizar ningún «pronunciamiento»—-, sino porque el gobierno de turno, al intentar acabar con ellas con la energía que dicta el Código de Justicia Militar, las hizo visibles ante la

28 VILLACORTA BAÑOS, 1989: 407.

29 VILLACORTA BAÑOS, 1989: 374.

30 Quien también vio que una petición de la colectividad armada adquiere inmediatamente el carácter de conminación y hace inútil la huelga fue PARDO GONZÁLEZ, 1930: 23: «La falta de interior satisfacción, procedente de males políticos y privados, era común a todos los funcionarios; pero los que disponían de las armas no habían de menester declararse en huelga; para ser atendidos les bastaba con elevar a la superioridad peticiones colectivas que, aun extremando el respeto en la forma, tenían, por venir de ellos, carácter y eficacia de amenaza conminatoria. Desde 1917 esas peticiones menudearon». 
sociedad civil. Eso acabó inmediatamente con aquel gobierno, pero a la larga también cavó la tumba de unas Juntas que de ninguna manera podían desenvolverse bien bajo los focos de la opinión pública, que esperaba de ellas nada menos que la regeneración del país.

Desde sus primeros pasos fueron tildadas de ser una copia inadmisible de las organizaciones sindicales de nuevo cuño que acaparaban el debate social y político de la época. Incluso una parte importante de la historiografía posterior ha hecho suyo ese diagnóstico. Pero los empleados públicos, fueran civiles o militares, e independientemente de sus retribuciones, se incluían a sí mismos entre las capas medias de la sociedad, en un lugar equidistante entre los poderosos y sus abusos, y los oprimidos y sus desafueros. Querían vivirse, en definitiva, al margen del conflicto social básico que enfrentaba a capitalistas y obreros. Por lo demás, la gran diferencia entre corporativismo y sindicalismo estriba en que éste último articula la solidaridad y defensa de sus afiliados frente al capital y frente al trabajo asalariado. En cambio el primero organiza el grupo, la clase, en sus relaciones con el conjunto de la sociedad, que se vive como un objeto separado, que puede llegar a ser hostil, y, sobre todo, frente a la concreción jurídico-política de esa sociedad: el Estado. Si las Juntas Militares de 1917 pueden considerarse un movimiento corporativo es porque pretenden proteger al grupo de las injerencias externas - de los aparatos estatales, sobre todo-, convirtiendo en dominio privativo el ejercicio de la función que ese grupo desarrolla, la cual termina convirtiéndose en una referencia ontológica más que en una simple prestación de servicios a la sociedad. Por lo tanto, el corporativismo irá más allá de la articulación de la solidaridad y defensa del grupo y se volcará en su revalorización con respecto a otros colectivos con los que concurre para atribuirse alguna de las funciones, recompensas y honores que dan forma a la vida social ${ }^{31}$.

La organización corporativa y la sindical pueden presentar en ocasiones una indudable identidad de formas. A menudo se han señalado los incrementos salariales obtenidos por las Juntas y su pretendida organización «democrática» como señales inequívocas de su carácter sindical, pero si revisamos los textos del movimiento juntista castrense veremos que las reivindicaciones salariales, sin ser negadas, nunca se concretan en cantidades contantes y sonantes, ni se sitúan como el objeto primordial de su actividad. Así, el famoso manifiesto fechado el 25 de junio de 1917 trata primero de las «cuestiones de orden moral», luego de las «cuestiones de orden técnico», y en tercer lugar de «las cuestiones económicas», «que espíritus mezquinos han podido creer eran las fundamentales de la Unión. No lo son, ni pueden, ni deben serlo». Si se habla de ellas en el manifiesto es para combatir el pluriempleo de los oficia-

\footnotetext{
31 VILLACORTA BAÑOS, 1989: 332-334.
} 
les, que compromete su excelencia profesional; la defección de buenos sargentos, que prefieren acogerse a los mejores salarios del mundo civil; $y$, sobre todo, para erradicar la miseria del soldado. Tal es el pudor de estos hombres -no se olvide nunca que ellos se consideran caballeros de uniforme-, que pueden llegar a afirmar en este mismo texto que «el mejoramiento económico no es sólo cuestión de aumento de sueldos: esto, como única solución sería la más cara y de menos eficacia», y terminar proponiendo una amplia panoplia de soluciones: desde la construcción de pabellones al desarrollo del cooperativismo, pasando por la permanencia y sencillez de los uniformes ${ }^{32}$.

Y para explicar la singularidad «democrática» de las formas organizativas de las Juntas de Infantería debe tenerse en cuenta la necesidad de reclutar y encuadrar el abultado número de sus integrantes - 5952, según el Anuario de 1917- distribuidos por toda la geografía nacional y el Protectorado marroquí, en un momento de incremento exacerbado de las necesidades de defensa corporativa del grupo. Una red de juntas locales — una en cada guarnición-; regidas y representadas las de cada distrito militar por una junta regional; y, de entre ellas, otra superior elegida al efecto para representar a toda el Arma ante la sociedad, los poderes públicos, y el resto del Ejército, parecía una buena organización: simple, sólida y flexible. Por otra parte, la afiliación obligatoria, con compromiso escrito de adhesión y mutuo amparo, la cotización mensual y la sombra ominosa y casi omnipotente de los tribunales de honor resultaron terriblemente eficaces para disciplinar esa nueva organización y conseguir de sus integrantes su plena identificación con las formas de desarrollo de la identidad profesional consideradas adecuadas en la propia autovaloración del grupo ${ }^{33}$.

Sin embargo, se daba un importante dilema organizativo: había que asegurar la participación y el compromiso masivo de todos, pero respetando al mismo tiempo la rígida organización jerárquica — de segundo teniente a coronel- de los miembros del colectivo castrense. O, dicho de otra manera: participación sin menoscabo de la disciplina; reconocimiento del peso de los más numerosos sin arrinconar en el desván de los trastos viejos a los que por su mayor jerarquía son inferiores en número. El peliagudo problema tenía un carácter

32 El texto del manifiesto de 25 de junio de 1917 en BUXADÉ, 1918: 98-113. Pocos días antes, el 15 de junio, EL DÍA (Madrid, 1916) publicaba en su p. 2 una entrevista con el coronel Márquez en la que éste aseguraba que las Juntas no pretendían ningún aumento de sueldo - contrariamente a otras juntas civiles-, considerando que la prosperidad del Ejército podía darse con los presupuestos entonces en vigor y sin nuevos tributos; y recordaba que si la aspiración juntera por antonomasia era la lucha contra los favoritismos, bajo ningún concepto querrían verse acusadas de levantar uno nuevo.

33 BENZO, 1931: 75-78. Se recogen algunas reflexiones éticas y jurídicas con respecto a la coacción que suponía la amalgama del compromiso de adhesión y los tribunales de honor sobre los adheridos a la Unión. 
y exigía soluciones más corporativas que democráticas. Y exigió compromisos: el reglamento fijaba que los miembros de una junta regional - y la Superior era una de las regionales - debían ser siete: 1 coronel, 1 teniente coronel, 1 comandante, 2 capitanes y 2 subalternos, es decir, tres jefes y cuatro oficiales, lo que suponía una mayor representación proporcional con respecto a su número de la clase de jefes, pero permitiendo que los oficiales fueran mayoría en la junta, como lo eran en el conjunto del colectivo militar. En cualquier caso, la presidencia era siempre para el coronel. Además, la compleja elección de cada uno de los integrantes de la junta quedaba exclusivamente en manos de sus compañeros del mismo empleo. Para evitar que los oficiales se impusieran siempre en las votaciones a los jefes, el artículo $3^{\circ}$ del reglamento sólo consideraba como acuerdos válidos aquellos que contaran con las dos terceras partes de los votos emitidos descontando las abstenciones. Asimismo, para que una proposición pudiera convertirse en «opinión del Arma» debía contar también, en cualquiera de los ámbitos de discusión, con las dos terceras partes de los votos emitidos descontando las abstenciones, pero, además, a fin de salvaguardar dos necesidades contradictorias: la disciplina y la libertad de criterio, el debate se articulaba en cada unidad de manera que los oficiales de diferente jerarquía no se mezclaran, iniciándose la discusión por los de rango más bajo, para evitar que se vieran cohibidos por la opinión de sus superiores. Resulta, pues, evidente que extender, mediante la red de juntas locales y regionales, un debate semejante a todas las unidades y establecimientos repartidos por el territorio nacional y Protectorado africano, tenía como consecuencia hacer descorazonadoramente lenta la adopción de proposiciones emanadas de las bases. Hubo que dejar necesariamente un amplio margen a la libertad de decisión de la Junta Superior para la gestión del día a día y la fijación provisional de la «opinión del Arma» ${ }^{34}$.

Aún así, se comprende que esta organización de nuevo cuño deslumbrara a empleados civiles y militares. Ya hemos visto que los primeros tendieron a arrinconar sus viejas asociaciones de funcionarios y a embarcarse en la organización de juntas por toda la geografía nacional. Otro tanto ocurrió con los segundos. Los cuerpos facultativos, excepto quizás los impertérritos ingenieros, comprendieron que corrían el riesgo de ser barridos y arrinconados por la capacidad de encuadramiento y movilización de las nuevas Juntas de Infantería, el arma más numerosa y combativa entonces. Sus viejas juntas no podían estar a la altura de las nuevas oportunidades surgidas de la aguda crisis del Estado de la Restauración porque resultaban ser, en realidad, tranquilos colegios profesionales que sólo se preocupaban del mantenimiento de la escala

34 El reglamento de la Junta de Infantería, escala activa, se encuentra en MARTÍNEZ DE ARAGÓN Y URBIZTONDO, 1923: 20-35 de los «Apéndices». Los artículos más importantes sobre organización son, entre otros, el $3^{\circ}, 12^{\circ}, 14^{\circ}, 19^{\circ}$ a $26^{\circ}, 30^{\circ}, 31^{\circ}, 36^{\circ}, 37^{\circ}, 46^{\circ}$ y $52^{\circ}$. 
cerrada y de la defensa de sus títulos facultativos en el mercado civil. Eran elegidas por el conjunto del escalafón entre los compañeros con destino en Madrid, sin cotización mensual, ni compromiso de adhesión y mutuo amparo, y sin el soporte, en su inicio, de una extensa red de juntas regionales y loca$\operatorname{les}^{35}$. Por lo tanto, y para mantener o, incluso mejorar, sus posiciones corporativas transformaron sus viejas organizaciones y también se sumaron a la nueva ola juntista con más o menos entusiasmo.

Finalmente, recordemos que el rasgo esencial del corporativismo es la defensa y revalorización del grupo frente a otros posibles colectivos rivales, frente al Estado o, incluso, frente a la sociedad misma, percibida entonces como una amenaza. Cubrir esa necesidad de manera óptima exige que el grupo se acerque a su autogobierno o, al menos, maximice su autonomía corporativa. Pero este autogobierno, al que propenden tanto las corporaciones civiles como las militares, sólo puede cimentarse sobre unos valores y conductas comunes, que garanticen su compromiso en la defensa del «honor» del grupo $y$, en definitiva, de su prestigio social. Nada de esto se puede conseguir sin el concepto fundamental de «Unión», verdaderamente clave para la cristalización del corporativismo, aunque a menudo oculte la efectiva fractura o segmentación del conjunto. En la galaxia castrense la «Unión» se erige sobre otro concepto sagrado: el «compañerismo», a veces coartada de la implacable tiranía de la corporación sobre el individuo. Con la «Unión» fruto del «compañerismo» se podrá ejercer control sobre las condiciones profesionales, sobre los derechos, deberes, recursos y recompensas de los integrantes del colectivo. Pero, sobre todo, se podrá apartar de él, a menudo sirviéndose de tribunales de honor, a los que no sepan encajar en el ordenamiento de la corporación. En palabras, una vez más del doctor Villacorta: «Bien puede decirse que la historia del corporativismo de esta época, en cualquiera de sus formas, fue la de su pugna por conseguir una auténtica facultad disciplinaria para sus organismos. $»^{36}$. Es por eso que el reglamento de la Junta de Infantería, escala activa, en sus artículos $4^{\circ}, 9^{\circ}, 18^{\circ}, 38^{\circ}, 39^{\circ}, 42^{\circ}$ y $44^{\circ}$, se muestra tan celoso de las cuestiones de honor y de los castigos necesarios para mantenerlo incólume, porque lo que está en juego es la gobernanza del grupo que dice representar. Y eso es exactamente lo que subyace en la desconcertante tozudez con que la Junta de Infantería, enajenándose simpatías civiles y militares, gestiona

35 PUELL DE LA VILLA, 1986: 111.

36 VILLACORTA BAÑOS, 1989: 327-331. La cita entrecomillada es de la p. 328. Las pp. 329-330 nos informan sobre la conquista del derecho a tribunales de honor por parte de algunos colectivos de funcionarios: los diferentes Cuerpos de Ingenieros en 1900; los Cuerpos del Profesorado en 1901; Telégrafos en 1903; Correos en 1909; Notarios en 1914; y funcionarios administrativos en 1918. En el Ejército, los tribunales de honor son más antiguos. Su primera regulación legal data de 1867, según PONCE ALBERCA y LAGARES GARCÍA, 2000: 46. 
el sonado caso de la expulsión del Arma de los alumnos de la Escuela Superior de Guerra, ocurrido en 1919 mediante un tribunal de honor. Parece, incluso, que si las Juntas congelaron su actividad poco antes del relevo del gobierno Romanones en abril de 1917 fue a cambio de que el general Luque, ministro de Guerra entonces, intentara domesticarlas dando forma a su proyecto de convertir a las nacientes Juntas en las depositarias del «honor del Arma», es decir, que ostentaran el monopolio de la gestión de los tribunales de honor ${ }^{37}$.

\section{LA JUNTA Y LA ESCALA}

Así pues, las Juntas de Defensa fueron la nueva expresión del corporativismo militar y no otra cosa. Pero el objeto de su defensa, la matriz humana sobre la que se sustentaban, no fue nunca el Ejército, ni sus armas y cuerpos, sino una entidad menor: las escalas en que se subdividían esos cuerpos y armas. Una ojeada rápida a cualquiera de los anuarios militares de aquellos años avalaría lo que acabamos de afirmar la realidad primaria en que se organiza el personal que en ellos se recoge son las escalas: la escala activa del Arma de Infantería, o la de Intendencia, o la escala de reserva de Caballería, o, que la de reserva retribuida de Ingenieros, o la del Estado Mayor General, etc. En realidad, podríamos definir las Juntas Militares como la organización corporativa de la que se dotó cada escala para su autogobierno, su defensa y su representación externa ${ }^{38}$. Entenderlo así nos permitiría explicar algunas cosas.

En primer lugar, aunque ya hemos visto más arriba las razones profundas de los oficiales de Infantería y Caballería para dejar fuera de su organización al generalato - precaverse de sus posibles manipulaciones caciquiles -, la justificación pública de su apartamiento consistió en el hecho de que los oficiales generales ya no pertenecían a la escala activa de las distintas armas y cuerpos ${ }^{39}$,

37 CONDE DE ROMANONES, 1947: 137, nota.

38 Recordemos, por ejemplo, que en el escrito enviado a 34 periódicos del país por aque1la fantasmal «Comisión Militar», surgida a primeros de 1910, probablemente en Barcelona, y en el que se denunciaban los ascensos de guerra de la campaña de Melilla, se llegaban a decir cosas como ésta: «Que se hacen hechos distinguidos y meritorios, recompénsense con cruces, con dinero, que éste es del Estado, pero no con el perjuicio de las escalas, porque éstas son el porvenir, el capital de la oficialidad del Ejército; éstas son propiedad nuestra y no del ministro de la Guerra» (la cursiva es nuestra), recogido en SECO SERRANO, 1984, 258. No se puede pedir un ejemplo más claro de patrimonialización de un instrumento administrativo. Seco considera esta fugaz «Comisión Militar» un antecedente claro de las Juntas de Defensa Militares que aparecerían siete años después.

39 Así se indica en el preámbulo del Reglamento de la Unión y Junta de Defensa del Arma de Infantería recogido en MARTÍNEZ DE ARAGÓN y URBIZTONDO, 1923: 21 de los «Apéndices». 
pues ésta integraba sólo a sus oficiales «particulares», es decir, de segundo teniente a coronel inclusive. Las Juntas nunca olvidarán que un general procedente de Infantería, por ejemplo, aunque dijera sentirse genuinamente vinculado al Arma, ya no pertenecía a ella, y supieron aprovechar este detalle para marginar al generalato, en un intento de democratizar el ejercicio profesional, la representación corporativa y el reparto de recursos y beneficios. $\mathrm{La}$ misma pugna contra la oligarquía y a favor de la democratización profesional se estaba dando durante estos años en otras carreras civiles de marcado carácter corporativo ${ }^{40}$. Por otro lado, no es que estos colectivos de profesionales, desde su rechazo al caciquismo, se negaran a utilizar las posibilidades que el padrinazgo de alguna figura partidista pudiera proporcionar para mejorar su encaje en la vida del Estado. La Artillería, por ejemplo, otorgó en 1916 la presidencia de su Junta Central al coronel Galarza, senador y correligionario de Romanones, aunque el nuevo vendaval juntero lo defenestró. Pero eso no será en absoluto viable en cuerpos muy numerosos como la Infantería, y, en cualquier caso, terminará comportando el continuo fracaso de reformas legislativas muy necesarias ${ }^{41}$. En este sentido, nos parece que las Juntas de 1917 nacieron cuando los cuerpos de oficiales tomaron conciencia del fracaso de sus intermediarios tradicionales - el rey y los generales políticos- en la puesta en marcha de reformas que les garantizaran carrera, salario y relevancia social. Las armas generales, además, terminaron sumando a ese reproche la lúcida constatación de que, en realidad, esos intermediarios tradicionales eran los principales causantes, con sus interesadas prácticas caciquiles, del deterioro de sus condiciones de vida y carrera. Como la figura del rey era en ese momento todavía intocable, las Juntas de Infantería se contentaron con perseguir a un puñado de generales especialmente odiado ${ }^{42}$.

En segundo lugar, al ser la escala el grupo profesional que cada Junta pretendía organizar y defender, cuerpos como la Infantería, la Caballería, la Artillería y los Ingenieros producirían más de una Junta de Defensa, con intereses no siempre coincidentes, porque, dentro de un mismo cuerpo, los oficiales de la escala activa - la procedente de la Academia - coexistían con los de la escala de reserva retribuida — los ascendidos desde las filas de tropa-. Incluso las mismas clases de tropa de algunos cuerpos tuvieron fugazmente sus propias Juntas, que fueron disueltas en enero de 1918 y expulsados del Ejérci-

40 VILLACORTA BAÑOS, 1989: 310-312.

41 VILLACORTA BAÑOS, 1989: 341-343. VIGÓN, 1947, vol. III: 242-248.

42 Uno de los primeros acuerdos de la denominada «Asamblea Magna» de las Juntas de Infantería consistirá en aplicar determinadas sanciones, por considerarlos enemigos de «La Unión», a los generales Alfau, Luque, Figueras, Carbó, Bazán, Aguilera, Riera y marqués de Estella, en HERALDO DE MADRID (Madrid) de 19 de octubre de 1917, p. 2, refiriéndose al 9 y 10 de agosto anterior. 
to sus miembros más significados. Tampoco los oficiales de la escala de reserva retribuida lo tuvieron fácil en el nuevo movimiento juntero. Los de Infantería, en un primer momento, intentaron incorporarse a la organización de sus colegas procedentes de la Academia. Pero no se les permitió la entrada y se les aconsejó que crearan sus propias Juntas ${ }^{43}$. Entonces buscaron el apoyo de las clases de donde procedían - las de tropa-, acercamiento que en África fue muy mal visto por el mando. Hubo que esperar a la creación de las Comisiones Informativas, en los primeros días de 1920, para que éstas decidieran incorporar en su seno a un único representante de la reserva retribuida. Aunque la Artillería y la Caballería así lo hicieron ese mismo año, la Infantería esperó a 1922, seguramente porque sólo en plena confrontación con los africanistas resultaba deseable una aproximación a la despreciada escala de reserva. En cambio, la Comisión de Caballería acabó por prescindir del representante de esa escala, debido a serias diferencias con sus miembros ${ }^{44}$. Queda claro que el elemento director en cada cuerpo, el de más elevado estatus corporativo, el de mayor consideración profesional y social, era su escala activa. Cuando nos referimos a las Juntas, nos referimos a «sus» Juntas. Las escalas activas terminaron suplantando a sus cuerpos respectivos en la conciencia de sus integrantes y en la literatura de la época; del mismo modo que la Infantería, por su número e influencia en la gestión del orden público, terminó suplantando a la totalidad del Ejército. Siguiendo esa lógica entendemos mejor la decisiva influencia de la Junta de Defensa de la Escala Activa del Arma de Infantería en el conjunto del movimiento juntista militar.

En tercer lugar, si cada una de las escalas de las distintas armas y cuerpos organizaba sus propias Juntas para la defensa de sus intereses, resultaba imposible levantar una organización unificada que representara a la totalidad de la corporación castrense, y es que no existía un escalafón general del Ejército que sustentase un organismo semejante. No sin tensiones y mutuas desconfianzas, se consiguió con el tiempo ir articulando algún tipo de coordinación entre las diferentes organizaciones junteras, y no en todas las ocasiones. Para empezar, el movimiento del 1 de junio de 1917 fue cosa exclusiva de infantes. Tanto la Junta Superior detenida en Barcelona, como las juntas locales y regionales que se solidarizaron con ella y se presentaron en un puñado de capi-

43 MÁRQUEZ; y CAPO, 1923: 184 (nº 7 del «Apéndice de documentos»). Los oficiales de la escala de reserva retribuida del Arma de Infantería no constituían una minoría irrelevante. En el anuario militar de 1917 las cifras eran: 5942 oficiales en la escala activa y 1980 en la de reserva retribuida.

44 ALONSO IBÁÑEZ, 2004: 413-415, 566-568 y 575-578. VIGÓN SUERODÍAZ, [s/f] AGMAV: 35 dice, en cambio, que las Comisiones Informativas decidieron el 17 de enero de 1921 incorporar a un representante de la escala de reserva retribuida, pero no como vocal, sino como enlace entre las Juntas de ambas escalas. 
tanías para ser arrestadas eran todas de Infantería ${ }^{45}$. Para que no quede ninguna duda, el día 11 de aquel mes de junio, la recién liberada Junta Superior de Infantería envió a la prensa un comunicado cuyo primer punto aclaraba «que no existe con ninguna denominación una junta constituida por las tres armas $y$, por lo tanto, nadie puede ostentar su representación. $\rangle^{46}$. Hubo que esperar al 12 de septiembre de aquel año en Zaragoza para que en su "Asamblea Magna» - como la denomina Alonso - las Juntas regionales de Infantería acordasen que «es aceptada, en principio, la acción mancomunada de todas las Armas y Cuerpos» ${ }^{47}$. Pero esa «acción mancomunada» se redujo a una problemática coordinación entre los presidentes de las distintas Juntas de ámbito estatal. Más no era posible: el artículo 36 del reglamento de la «Unión y Junta de Defensa de la Escala Activa del Arma de Infantería», aprobado ya en 1916, establecía que era únicamente el presidente de la Junta Superior quien debía sostener «lazos de unión y afecto con las Juntas de otras armas otorgán-

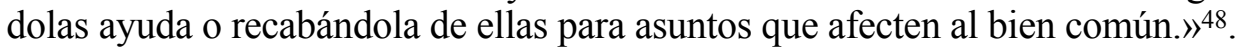

Esta coordinación de las distintas Juntas del Ejército, posibilitada sólo a través de los vértices superiores de sus organizaciones respectivas, se hizo por fin realidad en Barcelona el 8 de octubre con la Reunión de Presidentes de Juntas Regionales y Superiores de las Armas, Cuerpos e Institutos de Ejército, que se ocupó de diferentes cuestiones referidas a las clases de tropa y al generalato desafecto ${ }^{49}$. Pero ya a finales de ese mismo mes, quedó claro el carácter asambleario y coyuntural de esta coordinación, y la debilidad de los mecanismos conjuntos de toma de decisiones, en el encuentro convocado por la Infantería para recabar el apoyo de los otros cuerpos a un manifiesto, previamente aprobado por sus juntas locales y regionales, que debía dirigirse al monarca, y que finalmente acabó con el gobierno Dato. En la larga y tensa reunión, los convocantes se mostraron incapaces de imponer su texto a los asustados representantes de la Caballería, la Artillería, los Ingenieros y el Estado Mayor ${ }^{50}$.

La siguiente reunión de la Asamblea de Presidentes de las Juntas de todas las Armas y Cuerpos - catorce personas en total - tuvo lugar en marzo del año siguiente, tras la aprobación por decreto de una serie de reformas militares diseñadas para aplacarlas y obtener su autodisolución, y que poco después

45 ALONSO IBÁÑEZ, 2004: 112-117.

46 BUXADÉ, 1918: 95-96.

47 HERALDO DE MADRID (Madrid) de 19 de octubre de 1917, p. 2.

48 MARTÍNEZ DE ARAGÓN y URBIZTONDO, 1923: 29 de los «Apéndices».

49 ALONSO IBÁÑEZ, 2004: 175. Asisten representantes de los cuerpos de Carabineros, Intendencia, Estado Mayor, Sanidad, Guardia Civil, Artillería e Infantería. A destacar las ausencias de Caballería e Ingenieros.

50 ALONSO IBÁÑEZ, 2004: 178-180. MÁRQUEZ; y CAPO, 1923: 70-71 y 210-223. 
dieron lugar a la Ley de Bases para la Reorganización del Ejército de 1918. En el encuentro, la Infantería se impuso a la Artillería, al Estado Mayor y a los Ingenieros, siempre más proclives a no enfrentarse con el poder civil procediendo a la disolución solicitada. Las Juntas continuaron, aunque prometiendo al ministro La Cierva una actividad exclusivamente circunscrita a cuestiones profesionales. Durante el segundo semestre de ese año, sus presidentes ya habían adquirido la costumbre de reunirse todos los meses en una asamblea, a fin de coordinar su actuación y gestionar los conflictos y desacuerdos que pudieran existir entre los diferentes cuerpos ${ }^{51}$. Esa misma tónica fue la que imperó a lo largo de 1919, surgiendo, incluso, de la Asamblea de Presidentes de Juntas una Comisión Permanente. Durante el segundo semestre de aquel año, la Comisión Permanente y la Asamblea estuvieron ocupadas en discutir, a instancias fundamentalmente de la Infantería, sobre el futuro del cuerpo de Estado Mayor, extinción incluida; pero este cuerpo supo aprovechar su presencia en los órganos rectores del movimiento juntero para orquestar una decidida defensa de su supervivencia ${ }^{52}$. De este modo, la agresiva supremacía de la Infantería en las Juntas, no sólo iba dirigida contra los abusos de los gobiernos de turno, sino también contra los privilegios, supuestos o reales, de las otras armas y cuerpos. La presencia en los órganos de coordinación del fenómeno juntero de los cuerpos facultativos, sobre todo, se debía cada vez más a la constatación de la necesidad de seguir permaneciendo en ellos con el fin de defenderse de las pretensiones de los infantes, o de controlar sus inadecuadas, o incluso peligrosas, iniciativas. En los años inmediatos está dinámica se hará cada vez más evidente ${ }^{53}$.

A primeros de 1920, las Juntas obtenían su ansiada legalización gracias a un real decreto del gobierno Allendesalazar - y el general Villalba como ministro de la Guerra-, con el que se constituían unas denominadas Comisiones Informativas, tantas como armas y cuerpos, directamente dependientes de la subsecretaría del ministerio y en relación constante con los jefes de sección o directores generales ${ }^{54}$. La Comisión Permanente de la Asamblea de Presidentes de Juntas, que, por supuesto, no había recibido ningún tipo de reconocimiento en el nuevo decreto, continuó tranquilamente su vida, negociando con el subsecretario de Guerra las bases comunes a las que habrían de sujetar-

51 BOYD, 1990: 144.

52 ALONSO IBÁÑEZ, 2004: 534-547.

53 PARDO GONZÁLEZ, 1930: 63. El autor fue el representante del Cuerpo de Estado Mayor en la Comisión de Presidentes de Juntas tras la rota de Annual. Al tomar posesión del nuevo cargo nos dice que «Allí me encontré gente prudente, gente exaltada y también gente neutra, que llenaba su cometido sin entusiasmo, y sin otro fin que el de que su Cuerpo no careciera de representación». (La cursiva es nuestra).

54 El real decreto en el DIARIO OFICIAL DEL MINISTERIO DE LA GUERRA (a partir de ahora D.O.M.G.) nº 2 de 3 de enero de 1920. pp. 17-18. 
se los reglamentos particulares de cada Comisión Informativa. Las bases comunes estuvieron listas en agosto de aquel año, y merecen algún comentario. $\mathrm{Ni}$ en ellas ni en el real decreto al que hemos aludido antes se contemplaba ningún organismo superior de coordinación entre las distintas armas, cuerpos e institutos armados $-\mathrm{y}$ entre todos sumaban dieciséis, nada menos, con derecho a constituir su propia Comisión-. Resultaba muy sintomático que cuando en las bases se trataba de «conservar y acrecentar la unión y afectuoso compañerismo» se refiriese a conseguirlo exclusivamente dentro de «cada Arma, Cuerpo e Instituto». Entre estas entidades burocráticas no quedaba más que «estrechar los lazos y relaciones... cooperando así de modo eficaz al engrandecimiento del Ejército, para bien de la Patria». Naturalmente, la vigilancia del prestigio moral y del decoro de los individuos —es decir, la capacidad depuradora- era privativa de cada uno de los cuerpos ${ }^{55}$.

Sin embargo, a pesar de las buenas intenciones, la norma era la pugna entre las distintas Juntas cuando sus intereses se oponían, como en el caso de la querella sostenida entre los artilleros y los ingenieros debida a un proyecto sobre inspección de las industrias civiles - preparado por el nuevo ministro de la Guerra, Vizconde de Eza-, que daba preponderancia a éstos últimos en detrimento de los primeros. Aunque la Comisión de Presidentes propuso un comité arbitral, no se pudo impedir que hacia 1921 las Comisiones de ambos cuerpos rompieran sus relaciones. La unanimidad sólo era fácil cuando la disputa se mantenía contra una corporación externa al Ejército, como durante el pleito sostenido desde 1918 entre la Artillería y la Armada por el control de las bases navales ${ }^{56}$.

Tras el desastre de Annual se evidenciaron aún más las rencillas y la falta de entendimiento entre las Juntas o Comisiones de las distintas armas y cuerpos. Emergió a la luz pública entonces la línea de fractura que desde 1917 separaba la moderación de las Juntas de los cuerpos facultativos de la belicosidad de las armas generales. En el caso de los ingenieros, la irrupción de la avalancha juntera no cambió sus órganos de representación y autorregulación, ni su vida colectiva. Los artilleros, después del derrumbamiento de la comandancia de Melilla, dejaron que su jefe de sección en el ministerio se ocupara de las relaciones externas, mientras su Comisión entraba en un estado de animación suspendida, sólo roto para depurar las responsabilidades del cuerpo en los campos africanos ${ }^{57}$. Y en cuanto al cuerpo de Estado Mayor, de creer el testimonio del coronel Cándido Pardo — su representante en la Comisión de Presidentes-, era el que lideraba el bloque de oposición formado por él mismo, los Ingenieros y la Artillería, al que luego se adhirieron la Guardia Civil, el

\footnotetext{
55 ALONSO IBÁÑEZ, 2004: 563-565.

56 VIGÓN SUERODÍAZ, [s/f] AGMAV: 22, 23, 33, y 34. ALONSO IBÁÑEZ, 2004: 574.

57 ALONSO IBÁÑEZ, 2004: 576 y 583-584. VIGÓN SUERODÍAZ, [s/f] AGMAV: 38.
} 
cuerpo de Intervención, la Sanidad y la Intendencia, oposición que intentaba aislar en esa Comisión de Presidentes a la Infantería y a la Caballería ${ }^{58}$.

La crisis final vino por el enfrentamiento entre la Comisión de Infantería y La Cierva, nuevamente ministro de Guerra. A primeros de enero de 1922, los infantes de la Península exigieron su dimisión en una tormentosa entrevista entre el ministro y los presidentes de las Comisiones Informativas, la mayoría de las cuales intentaron mediar en la disputa. La Infantería se quedó sola; la crisis se superó en bien del poder civil por el apoyo que el gobierno recibió del Ejército de África, explicitado en un telegrama firmado por la mayoría de los jefes de cuerpo allí destacados; y las Comisiones Informativas vieron remodeladas por segunda vez las bases legales de su constitución. Ahora su número se elevaba a $16 \mathrm{y}$, sorprendentemente, la nueva reforma decretada por La Cierva legalizaba, por fin, el entramado de juntas locales y regionales extendido por todas las guarniciones del país, tan característico del fenómeno juntero ${ }^{59}$. Daba igual, ante el poder civil ya solo quedaba en pie la Junta de Infantería, pero esa era la más numerosa y la más decidida. Sin embargo, el fin estaba próximo. Su aislamiento del resto del Ejército y su enfrentamiento con la opinión pública las dejaron en mala situación frente a los oficiales africanistas, que ahora concitaban las esperanzas de una buena parte de la sociedad española. Las Juntas perdieron esta última batalla y fueron disueltas oficialmente a finales de aquel año de 1922.

\section{LA ESCALA Y ÁFRICA}

La realidad de los hechos históricos es la prueba de laboratorio que nos permite corroborar lo que venimos diciendo: que las Juntas Militares de 1917 fueron el resultado organizativo del corporativismo centrado en la escala; que la escala, a su vez, se constituyó en el centro de convivencia de sus integrantes, recogiendo la mayor parte de su lealtad corporativa, porque, si se basaba en la antigüedad y quedaba libre de injerencias externas, resultaba ser el mejor garante de sus carreras profesionales. Sólo si comprendemos esto podremos explicarnos la respuesta, de una aplastante lógica corporativa, que se intentó dar al peor peligro que amenazaba a la «Unión» — concepto que ahora sabemos sagrado - de los componentes de las escalas activas de las armas generales. Ese peligro eran los ascensos por méritos de guerra otorgados en Marruecos, pues suponían un riesgo mortal para las carreras de la mayor parte de los oficiales - no olvidemos que el ascenso de uno significaba la postergación de todos

58 PARDO GONZÁLEZ, 1930: 63-65.

59 D.O.M.G. $\mathrm{n}^{\mathrm{o}} 13$ de 17 de enero de 1922, p. 169 y D.O.M.G. $\mathrm{n}^{\mathrm{o}} 19$ de 25 de enero de 1922, pp. 246-247. 
los que hasta entonces le habían antecedido en la escala—. Este fue uno de los principales motivos de disgusto militar en los años anteriores a la aparición de las Juntas y, sin duda, una de las causas más relevantes de su constitución.

Como sabemos, en la base 10 de la Ley de Reorganización del Ejército de 1918 los ascensos de guerra habían quedado en manos de Las Cortes, a fin de demostrar a las Juntas que todo favoritismo en su concesión había terminado. Pero las Juntas no se conformaron con ello y, simplemente, los paralizaron. Con la reanudación de las operaciones en el Protectorado marroquí, ahora el enfado se apoderó del puñado de oficiales africanistas que se estaba formando en ellas. Aunque los oficiales peninsulares y sus Juntas gozaban de una evidente posición de fuerza, no podían desconocer ni acallar el descontento de sus compañeros más comprometidos con la aventura africana. Urgía algún tipo de solución, más allá de leyes impuestas, que no fuera meramente coyuntural. Volvió a emerger, reflotada, la vieja propuesta, inequívocamente corporativa, de separar las escalas, de forma que los ascensos de guerra se produjeran fuera de las escalas de origen, tal vez en una nueva, propia de la especialidad colonial. La idea se remonta a los primeros chispazos provocados por el reavivamiento de la cuestión de las recompensas durante la campaña de Melilla de 1909, y aunque apareció por primera vez en un medio de prensa civil, La Correspondencia de España, en forma de un supuesto proyecto hallado en una papelera del ministerio de la Guerra, La Correspondencia Militar la hizo inmediatamente suya, y anduvo apareciendo con cierta regularidad en sus páginas ${ }^{60}$, y de vez en cuando en las de la prensa generalista durante estos primeros años de las campañas marroquíes. Nada verdaderamente extraño, pues en realidad significaba referirse al acreditado modelo francés que, según se decía, mantenía en escala separada a su oficialidad colonial. Por ello, no resultó sorprendente que muy poco después de la gira del ministro Eza por el Protectorado, en julio de 1920, La Correspondencia Militar mencionara de pasada la necesidad de separar las escalas en un editorial dedicado a las reformas ineludibles en el Ejército de África ${ }^{61}$. Sin embargo, lo

60 BRU SÁNCHEZ-FORTÚN, 2012: 69-70.

${ }^{61}$ LA CORRESPONDENCIA MILITAR de 11 de agosto de 1920, p. 1. Pero durante estos años no sólo se abunda en el tema de las escalas separadas desde la prensa político-militar, también las revistas profesionales castrenses se ocupan de ello en algún momento. Por ejemplo, en el MEMORIAL DE INFANTERÍA. Año X, Tomo XIX, nº 112 de mayo de 1921 aparece en pp. 319-329 un trabajo titulado «Nuestra acción en Marruecos» del capitán de Infantería Eduardo Sáenz Aranaz, que en p. 328 plantea la necesidad de que el cuerpo de oficiales del futuro ejército colonial sirva en escala independiente de la de sus compañeros peninsulares, por el resto de su vida militar o hasta el ascenso a general. El «Memorial» fue elegido en 1917 como la revista profesional de la Junta de Defensa de Infantería. La cuestión se plantea también en obras de mayor enjundia como la del capitán de Caballería RAMOS WINTHUYSSEN, Javier: Tropas Indigenas y Ejército Colonial, Sevilla, Lit. Tip. Gómez Hnos, 1921. 
que no trascendió al público fue que de marzo de 1920 a marzo de 1921 dormitó en alguno de los cajones de la mesa del Alto Comisario un proyecto de bases del Estado Mayor Central para la creación de un ejército colonial en África, que dejaba en excedencia en sus escalas de origen, lo que seguramente les obligaría a constituir las suyas propias, a los futuros jefes y oficiales que formaran parte de él, a cambio, eso sí, de doble sueldo y otras ventajas materiales, sin que se ofreciese o se negase en parte alguna la posibilidad de obtener recompensas y ascensos de guerra ${ }^{62}$. Esa solución complacía a las Juntas, y la subterránea existencia de ese proyecto explica la poca atención que dedicó al Ejército de África la reforma de 1918 - El proyecto lo terminó el E.M.C. a finales de aquel año-. Ni que decir tiene que el Alto Comisario, que entonces representaba los intereses de sus subordinados a favor de las recompensas de guerra frente a las restricciones impuestas por las Juntas ${ }^{63}$, lo dejó morir en el cajón sin informarlo, luego lo devolvió tranquilamente a Madrid por obsoleto, y Eza lo archivó como un posible antecedente para cuando se encarara definitivamente la obra de organizar un verdadero ejército colonial. No llegó a cuajar, por lo tanto, ningún tipo de pacto, o siquiera modus vivendi, entre la oficialidad peninsular y la colonial sobre la base de crear dos ejércitos distintos, uno dedicado a la defensa de las fronteras nacionales y otro a la ocupación del Protectorado, con escalas separadas, y en el que las recompensas de guerra obtenidas en Marruecos no perjudicaran a los desinteresados del sueño africano. Quizás fuese por ello que el 30 de abril de 1921, semanas después de que el Alto Comisario devolviera al ministerio sin informar las bases elaboradas por el E.M.C., las Juntas de Infantería tomaran la decisión de obligar a sus asociados — entonces todavía la totalidad de la escala - a

Trabajo premiado por el ministerio de la Guerra que, aunque escrito antes del desastre de Annual, se publicó poco después. Curiosamente, es el libro de un hombre ligado a los Regulares, que defiende la escala colonial separada y de por vida, pero exige la máxima largueza en la concesión de recompensas de todo tipo, sean al simple valor o a la acreditada pericia. Naturalmente también podríamos citar opiniones en contra de la separación de escalas, como la de el CAPITÁN BERENGUER: El Ejército de Marruecos: obra premiada en el concurso celebrado en el Ministerio de la Guerra (R.D. de 31 de agosto de 1921), Tetuán, Editorial Hispano Africana, 1922. Con esta larga nota sólo tratamos de llamar la atención sobre un debate profesional, cargado de tensiones corporativas, poco conocido, y que merecería todo un trabajo aparte.

62 Estudio de un proyecto de bases para la creación del ejército colonial de África, AGMS, Sección 2a, División 10a , Legajo 21: ver bases $89^{\mathrm{a}}, 90^{\mathrm{a}}, 91^{\mathrm{a}}, 92^{\mathrm{a}}, 93^{\mathrm{a}}, 94^{\mathrm{a}}$ y $95^{\mathrm{a}}$; en las páginas finales se pueden observar las idas y venidas del proyecto hasta su archivo final. $\mathrm{Su}$ estudio preparatorio a cargo del Estado Mayor Central en Proyecto de creación del Ejército colonial de África, AGMS, Sección 2a, División 10a, Legajo 20, con un voluminoso estudio de plantillas.

63 Ver, por ejemplo, la segunda carta que el Alto Comisario, general Berenguer, envía al ministro de la Guerra, general Tovar, con fecha 30 de julio de 1919, en BERENGUER, 1948: 192-193. 
renunciar a cualquier ascenso de guerra que pudiera corresponderles. No en mi escala, debieron pensar.

\section{CONCLUSIÓN}

Las Juntas de Defensa no pretendieron ser otro episodio más del crónico intervencionismo militar en la vida política española, que parecía volver por sus fueros con la imposición de la Ley de Jurisdicciones, durante la crisis de 1905-1906. Su forzada aparición a la luz pública no constituyó un verdadero «pronunciamiento». En cambio, tuvo más que ver con los costes derivados del desarrollo, por parte de las clases dominantes de la Restauración, de un Estado pretendidamente moderno, pero basado, en realidad, en las relaciones clientelares propias de un sistema caciquil. Al igual que otros grupos profesionales y funcionariales civiles, los oficiales del Ejército intentaron proteger de agresiones externas su salario, su carrera y su relevancia social, y apostaron por patrimonializar el ejercicio profesional prestado al Estado $-\mathrm{y}$ lo mismo intentaron entonces, con más éxito, corporaciones tales como notarios, ingenieros o médicos-, con la intención de obtener la máxima autonomía corporativa y defenderse quizás de futuras reformas que, aunque neutralizadas hasta entonces por la inoperancia del propio sistema político, podían terminar suponiendo la necesaria reconversión de la defensa nacional, pero también la destrucción de sus expectativas de empleo y carrera. Todo ello puso en crisis la intermediación tradicional de la Corona y de un puñado de generales políticos en las relaciones entre la corporación castrense y el Estado y la sociedad civil, con riesgo gravísimo para las instituciones, dado que el mantenimiento del statu quo con las armas en la mano resultaba ser el peculiar servicio prestado por los profesionales de la milicia. Pero aunque los gobiernos podían caer a sus pies, las Juntas no tuvieron ideales políticos concretos más allá de un nebuloso regeneracionismo anticaciquil, sólo reivindicaciones corporativas; ni en modo alguno su protesta podía constituir un avance en la conformación del Estado contemporáneo, sino un terrible tumor causado por el clientelismo que aquejaba al Estado de la Restauración, alejándolo de su camino hacia la modernidad.

Por otro lado, sería un error desconocer la sobreabundante diversidad de la galaxia castrense, su atomización en entidades tales como: generales, jefes, oficiales, clases de tropa, ejército de provincias, de Madrid, de África, armas generales, cuerpos facultativos, cuerpos auxiliares, escala activa, escala de reserva retribuida, etc. ${ }^{64}$, a menudo enfrentadas entre sí por el mantenimiento

64 Parece ser que llegó a existir una junta de diplomados de estado mayor, que todavía subsistía en enero de 1920, a pesar de que dos años antes la Junta de Infantería les había intimado a disolverse. Ver ALONSO IBÁÑEZ, 2004: 547 y 555, nota 83. 
o mejora de su esfera exclusiva. Cuando, emancipados de tutelas anteriores, los oficiales del Ejército decidieron dotarse de organizaciones corporativas propias, adoptaron un modelo piramidal, pero de masas, y extendido por todo el territorio, capaz de optimizar las capacidades de lucha corporativa del grupo, pero cuya matriz esencial no fue el propio Ejército, ni los distintos cuerpos, sino cada escala en particular, porque la escala resultaba ser a la postre el verdadero bastión de su vida colectiva y de su carrera profesional, y por ello recibía casi toda la lealtad corporativa de sus integrantes. De ahí el plural de «Juntas». Cada Junta fue, por tanto, la expresión orgánica del corporativismo de un grupo de profesionales que apostaron por su propio autogobierno, no sólo frente al Estado, sino también frente a otros grupos más o menos afines, incluso frente aquellos con los que compartía la galaxia castrense y también se organizaban en Juntas.

Por lo tanto, las Juntas de Defensa no fueron en principio una plasmación orgánica de la unidad corporativa del Ejército - como alguno hubiera podido creer-, sino la manifestación de su profunda desunión, aunque también, al mismo tiempo, el mecanismo que posibilitó sobrellevarla lo mejor posible, mediante la trabajosa construcción de instancias que posibilitaran la administración de los desacuerdos entre los diferentes grupos o la coordinación de sus esfuerzos, mejor o peor mancomunados, frente a un mundo exterior potencialmente adverso, fuera la clase política, otros colectivos funcionariales o la misma sociedad civil 65 .

\section{BibLIOGRAFÍA}

Alonso Ibáñez, Ana Isabel, Las Juntas de Defensa Militares: 1917-1922, Madrid, Ministerio de Defensa, Secretaría General Técnica, Servicio de Publicaciones, 2004.

65 Especialmente revelador del mutuo recelo entre las Juntas es el testimonio de VIGÓN SUERODIAZ, [s/f] AGMAV: 27 «Dicen algunos que no era posible disolver una Junta mientras las demás subsistiesen, porque entonces los intereses del Cuerpo que disolviese la suya quedarían abandonados»; e Ibídem: 29, dándonos una idea clara de la constante necesidad de pactar o de administrar los desacuerdos en el seno de los organismos conjuntos, recoge un fragmento del escrito de la Comisión permanente del Cuerpo de Estado Mayor dirigido «A nuestros compañeros del Ejército», en que, refiriéndose al pleito de su desaparición y conversión en servicio, confesaba:«Desde que se ha instaurado el nuevo régimen militar, todas las cuestiones orgánicas o de interés corporativo se han llevado al seno de las Juntas o a la Asamblea de Presidentes, en las que no es novedad decir que muchas cuestiones se han solventado, incluso dando a algunas estado oficial, por mutuas concesiones; que por temor a graves rozamientos no se han planteado otras, y que más que el interés general acomodado a los verdaderos principios militares, ha prevalecido en la mayoría de los casos el do ut des como suprema ley jurídica en el fallo de los pleitos familiares» (19-IX-1919). (La cursiva es nuestra). 
Benzo, Eduardo, Al servicio del Ejército: tres ensayos sobre el problema militar de España, Madrid, Javier Morata, 1931.

Berenguer, Dámaso, Campañas en el Rif y Yebala, 2 vols., Madrid, Ediciones Ares, 1948.

Boyd, Carolyn P., La politica pretoriana en el reinado de Alfonso XIII, Madrid, Alianza Editorial, 1990.

Bru Sánchez-Fortún, Alberto, «Padrino y Patrón. Alfonso XIII y sus oficiales», Hispania Nova. Revista electrónica de Historia Contemporánea, [en línea]. 6 (2006). Disponible en: http://hispanianova.rediris.es/6/articulos/6a003.pdf [consultado el 14 de noviembre de 2014].

Bru Sánchez-Fortún, Alberto, «El debate sobre el ejército colonial en España: 19091914», Revista de Historia Militar, LVI, 112, (Madrid 2012): 65-124.

Buxadé, Josep, España en crisis: la bullanga misteriosa de 1917: historial crítico de ella, formado con documentos, versiones y hechos notorios: un crimen político más, Barcelona, Imprenta de B. Bauzá, 1918.

Cachinero, Jorge, «Intervencionismo y reformas militares en España a comienzos del siglo XX» en Cuadernos de Historia Contemporánea, 10, (Madrid 1988): 155-184.

Capel, Horacio; Sánchez, Joan Eugeni; y Moncada, Omar, De Palas a Minerva: la formación científica y la estructura institucional de los ingenieros militares en el siglo XVIII, [Barcelona], Serbal, [Madrid], C.S.I.C, 1988.

Cardona, Gabriel, El problema militar en España, Madrid, Historia 16, 1990.

Carrasco Canals, Carlos, La Burocracia en la España del siglo XIX, Madrid, Instituto de Estudios de Administración Local, 1975.

Conde De Romanones, Notas de una vida (1912-1931), Madrid, Espasa-Calpe S.A., 1947.

Fernández Bastarreche, Fernando, El ejército español en el siglo XIX, Madrid, Siglo XXI, 1978.

Kindelán, Alfredo, Ejército y política, Madrid, M. Aguilar editor, 1947.

Lacomba Avellán, Juan Antonio, La crisis española de 1917, Madrid, Editorial Ciencia Nueva, 1970.

Márquez, Ex Coronel; y Capo, J.M., Las Juntas Militares de Defensa, Organización: Actuación, Derivaciones políticas e internacionales, Negocios de la guerra, La revolución en Cataluña y Asturias, Conminación de abdicación formulada por Inglaterra, Otros aspectos interesantes de la emoción revolucionaria de 1917, Barcelona, Librería Sintes, 1923.

Martínez de Aragón y Urbiztondo, Gabriel, Páginas de Historia Contemporánea: Las Juntas militares de Defensa; Los alumnos de la Escuela de Guerra; Los hombres públicos de España; La soberanía de la ley, Madrid, Librería de Alejandro Pueyo, 1923

Moral Ruiz, Joaquín del; Pro Ruiz, Juan; y Suárez Bilbao, Fernando, Estado y territorio en España, 1820-1930: la formación del paisaje nacional, Madrid, Catarata, 2007.

Pabón, Jesús: Cambó. 1876-1918, Barcelona, Editorial Alpha, 1952, vol. I.

Pardo González, Cándido, Al servicio de la verdad: Las Juntas de Defensa Militares: El Protectorado de Marruecos y Alhucemas: La dictadura del segundo Marqués 
de Estella: Aportaciones para un estudio critico de la Dictadura del General Primo de Rivera. Tomo I, Madrid, REHYMA, 1930.

Payne, Stanley G., Los militares y la política en la España contemporánea, [París], Ruedo Ibérico, 1968.

Ponce Alberca, Julio; y Lagares García Diego, Honor de oficiales: Los tribunales de honor en el ejército de la España contemporánea: (siglos XIX-XX), Barcelona, Ediciones Carena, 2000.

Puell de la Villa, Fernando, «Las Fuerzas Armadas en la crisis de la Restauración. Las Juntas Militares de Defensa» en Hernández Sánchez-Barba, Mario y Alonso Baquer, Miguel (dirs.), La Restauración. 81-126. Vol. V de Las Fuerzas Armadas españolas. Historia institucional y social, Madrid, Editorial Alhambra S.A., 1986.

Puell de la Villa, Fernando, Historia del ejército en España, Madrid, Alianza Editorial S.A., $1^{\mathrm{a}}$ ed., 2000.

Puell de la Villa, Fernando, «El ejército y la España de Isabel II», en Aproximación a la historia militar de España. Vol. 2. [Madrid], Ministerio de Defensa, Dirección General de Relaciones Institucionales, 2006.

Seco Serrano, Carlos, Militarismo y civilismo en la España contemporánea, Madrid, Instituto de Estudios Económicos, 1984.

Soldevilla, Fernando, El año político (1900). Año VI, Madrid, Imprenta y Fotograbado de Enrique Rojas, 1901.

Villacorta Baños, Francisco, Profesionales y burócratas. Estado y poder corporativo en la España del siglo XX, 1890-1923, Madrid, Siglo XXI de España Editores, S.A., 1989.

Vigón Suerodíaz, Jorge, Breves notas para la historia de las Juntas de Defensa y de la Dictadura por el General Don Jorge Vigón Suerodíaz, documento mecanografiado inédito en Archivo General Militar de Ávila, C.83,8,1. [s/f]

Vigón, Jorge, Historia de la Artillería Española, 3 vols., Madrid, C.S.I.C, Instituto Jerónimo Zurita, 1947.

Recibido: $12 / 12 / 2014$

Aprobado: 27/03/2015 